\title{
СИСТЕМА ПРАВОВЫХ СРЕДСТВ ФОРМИРОВАНИЯ ПРАВОВОГО РЕЖИМА ЦИФРОВОЙ ВАЛЮТЫ: ПРЕДПРИНИМАТЕЛЬСКО-ПРАВОВОЙ АСПЕКТ
}

\section{THE SYSTEM OF LEGAL MEANS OF FORMING THE LEGAL REGIME OF DIGITAL CURRENCY: THE ENTREPRENEURIAL-LEGAL ASPECT}

D. Nikitin

Summary. The article examines the system of legal means that form the legal regime of digital currency from the standpoint of the entrepreneurial and legal aspect. The author classifies legal means on the basis of correlation with civil turnover in time for means of preliminary, current and subsequent control. As a result of the study, the author offers some conclusions about the civil legal regime of digital currency and about the characteristics of the current state of the legal regime of digital currency in general.

Keywords: digital currency, entrepreneurial-legal aspect, legal regime, legal remedy, civil turnover.

\author{
Никитин Дмитрий Владимирович \\ Аспирант, Казанский (Приволжский) федеральный \\ университет \\ nikitin_d.v@list.ru
}

Аннотация. В статье рассматривается система правовых средств, формирующих правовой режим цифровой валюты с позиции предпринимательско-правового аспекта. Автором проводится классификация правовых средств по признаку соотношения с гражданским оборотом во времени на средства предварительного, текущего и последующего контроля. В результате исследования автором предлагаются некоторые выводы 0 гражданско-правовом режиме цифровой валюты и о характеристике нынешнего состояния правового режима цифровой валюты вообще.

Ключевые слова: цифровая валюта, предпринимательско-правового аспект, правовой режим, правовое средство, гражданский оборот.

о ЦФА») [2]. Закон о ЦФА вместе с положениями некоторых законопроектов (Проект Федерального закона № 1065710-7 «О внесении изменений в части первую и вторую Налогового кодекса Российской Федерации» (в части налогообложения цифровой валюты) [3], Проект федерального закона «О внесении изменений в Уголовный кодекс Российской Федерации и Уголовно-процессуальный кодекс Российской Федерации» ID проекта 02/04/03-16/00046853 [4], Проект федерального закона «О внесении изменений в Кодекс Российской Федерации об административных правонарушениях» ID проекта 02/04/10-20/00108949 [5]), образуют правовую базу для правового регулирования в среднесрочной перспективе.

Очевидно, что ни среди действующих, ни среди перспективных источников правового регулирования нет Гражданского кодекса. В связи с этим возникает ряд закономерных вопросов о том, приводит ли такое положение к выводу об отсутствии сейчас гражданско-правового режима цифровой валюты, какой правовой режим с точки зрения его отраслевой принадлежности на данный момент наиболее целостно представлен, а также о том, можно ли Закон о ЦФА классифицировать как источник правового регулирования гражданского обо- 
рота цифровой валюты. Начать решение поставленных задач необходимо с вычленения из всего имеющего сейчас правового материала конкретных правовых средств, которые и являются структурными элементами любого правового режима [6].

Представляется правильным расположить эти правовые средства не в случайной последовательности, a, применяя предпринимательско-правовую теорию разделения государственного контроля (надзора) на предварительный, текущий и последующий, отнести каждое правовое средство в соответствующую стадию. При этом заранее обозначив, что в рамках нашего научного исследования будет использован следующий подход: правовое регулирование на предварительной стадии как бы предшествует гражданскому обороту, текущий - сопутствует, а последующий - соответственно осуществляется после непосредственно завершения гражданского оборота между конкретными субъектами по поводу конкретного объекта.

1. На данный момент наименьшее число правовых средств удалось вычленить именно в рамках правового регулирования на стадии, которая предшествует гражданскому обороту.

1.1. Правовое средство в виде запрета на рекламу цифровой валюты (запрет на распространение информации о предложении и (или) приёме цифровой валюты в качестве оплаты за товары, работы или услуги) предшествует самим отношениям по обороту цифровой валюты и по своей природе не оказывает регуляторного воздействия на гражданский оборот цифровой валюты.

1.2. Признание цифровой валюты «иностранным финансовым инструментом» в рамках норм Федерального закона «О запрете отдельным категориям лиц открывать и иметь счета (вклады), хранить наличные денежные средства и ценности в иностранных банках, расположенных за пределами территории Российской Федерации, владеть и (или) пользоваться иностранными финансовыми инструментами» [7]. Путём применения такой правовой фикции, по существу, устанавливается запрет определённой категории граждан владеть и пользоваться цифровой валютой, а значит, эти субъекты априори выбывают из числа потенциальных участников гражданского оборота цифровой валюты.

Несмотря на малочисленность правовых средств в данной группе, позволим себе предположить, что после принятия специального федерального закона (который должен установить правовое регулирование выпуска и обращения цифровой валюты согласно пункту 4 статьи 14 Закона о ЦФА) данная группа правовых средств значительно пополнится. Такой вывод обосновывается тем, что правовое регулирование на стадии предшествующей непосредственно экономической деятельности в той или иной области как правило осуществляется путём установления различных правовых средств в виде требований к статусу субъекта (лицензирование, саморегулирование, государственная регистрация, обязательное страхование, требования к объёму уставного капитала, организационно-правовой формы и иное). Требования к статусу участников обращения цифровых финансовых активов уже сейчас установлены Законом о ЦФА, а установление аналогичных требований к участникам оборота цифровой валюты следует ожидать в самое ближайшее время.

2. Далее несколько нарушим последовательность и перейдём к правовым средствам, применяющимся после завершения экономической деятельности субъектов, которая заключается в обращении цифровой валюты.

2.1. Признание цифровой валюты имуществом для целей антикоррупционного законодательства. Статьи 22 Закона о ЦФА признают цифровую валюту имуществом для целей Федерального закона «О противодействии коррупции». Статья 24 Закона о ЦФА включает цифровую валюту в перечень объектов, сведения о которых должен государственный служащий. Каждая из приведённых выше правовых норм не оказывает непосредственного регуляторного воздействия на гражданский оборот цифровой валюты, а лишь возлагает обязанность по предоставлению соответствующих деклараций на определённый перечень субъектов.

2.2. Признание цифровой валюты имуществом для законодательства о несостоятельности (банкротстве). Данное правовое средство позволяет включить цифровую валюту в состав конкурсной массы должника, что, однако, в рамках судебной практики уже было возможно и без наличия данной нормы. Норма статьи 19 Закона о ЦФА, как и все остальные нормы правового институт банкротства, применяются как правило лишь после завершения экономической деятельности субъекта.

2.3. Признание цифровой валюты имуществом для целей законодательства об исполнительном производстве устанавливает теоретическую возможность обратить взыскание на такую разновидность «имущества» должника. Однако в законе отсутствует необходимый для этого механизм реализации такой возможности в виде принудительного обращения взыскания на цифровую валюту.

Рассматриваемое правовое средство является частью института исполнительного производства, которое является финальной стадией арбитражного или 
гражданского процесса, который в свою очередь основан на материальных правоотношениях и не может им предшествовать. Ввиду этого данное правовое средство можно отнести лишь к числу средств последующего контроля.

Примечательно, что юридическую несостоятельность двух последний правовых средств по целому перечню правовых оснований уже фактически констатировал сам же законодатель, но сделано это было не в момент обсуждения и принятия Закона о ЦФА, а во время первого чтения Законопроекта о налогообложении цифровой валюты [8].

2.4. Возложение на резидентов позитивной обязанности по декларированию цифровой валюты устанавливается как нормами пункта 6 статьи 14 Закона о ЦФА, так и специальными положениями в законопроекте о налогообложении цифровой валюты [3]. Несмотря на вышеуказанную жёсткую критику положений законопроекта о налогообложении цифровой валюты, в отношении данного правового средства можно с уверенностью утверждать, что такое правовое средство будет обязательно принято законодателем. А проводя классификацию, данное правовое средство, как и всякое другое декларирование будет безусловно относится к мерам последующего контроля.

На этом действующие правовые средства правового регулирования на последующей стадии исчерпаны и дальше будут приведены лишь правовые средства из имеющихся сейчас законопроектов.

2.5. Признание цифровой валюты имуществом для целей налогового законодательства. Данное правовое средство пока не получило законодательного закрепления, а лишь является положением законопроекта о налогообложении цифровой валюты [3]. При этом в отношении такого правового средства резко против высказались уже не только Комитет Государственной Думы по государственному строительству и законодательству [8], но и Комитет Государственной Думы по бюджету и налогам [9], а также Правовое управление Аппарата Государственной Думы [10]. В связи с этим перспективы принятия вышеуказанной нормы в нынешней редакции крайне невелики.

Правовые последствия признания цифровой валюты имуществом в рамках налогового законодательства пока что не вполне очевидны, но можно предположить, что тем самым цифровая валюты будет объектом налогообложения, правда не понятно какого именно налога. Если же наше предположение верно, то такое правовое средство, как и налогообложение в целом вполне обосновано можно отнести к средствам последующего контроля.
2.6. Наделение ФНС правомочием по истребованию сведений по банковским операциям, если последние связаны с операциями по переводу цифровой валюты. Данное правовое средство лишь опосредовано связано с обращением цифровой валюты и не направлено на регулирование непосредственно гражданского оборота цифровой валюты, но, вместе с этим, является специальным правовым инструментом, применяющимся исключительно только в рамках криптовалютных отношений.

Следует отметить, что с юридической точки зрения данный правовой инструмент в нынешнем его виде (по состоянию законопроекта на март 2021 года) имеет ряд проблем и неточностей, о чём было заявлено на стадии первого чтения законопроекта о налогообложении цифровой валюты [8] [9]. В связи с чем перспективы его принятия не очевидны.

2.7. Исключение операций, связанных с обращением цифровой валюты, из перечня объектов налогообложения по НДС. Следует особо отметить, что в случае принятия соответствующей нормы это было бы хорошим примером апробации наилучшего европейского опыта отечественным законодателем, поскольку Решением Суда Европейского союза по делу Hedqvist цифровая валюта и операции с ней также исключены из числа объектов НДС [11].

2.8. Признание цифровой валюты не амортизируемым объектом. В случае принятия данной нормы законопроекта о налогообложении цифровой валюты, последняя будет включена в перечень не амортизируемых объектов наряду с ценными бумагами и производными финансовыми инструментами.

Примечательно, что ранее нами уже упоминалось, что цифровая валюта признаётся иностранным финансовым инструментом, а в этом случае будет рассматриваться в одном ряду с производными финансовыми инструментами. В связи с чем теоретически возникает коллизия: является ли цифровая валюта финансовым инструментом или нет и может ли этот объект быть одновременно иностранным финансовым инструментом и не быть производным финансовым инструментом.

В любом случае, все правовые средства, предназначенные непосредственно и исключительно лишь для целей налогообложения, относятся к мерам последующего контроля.

3. После выделения правовых средств в группы предварительного и последующего правового регулирования намного проще обосновать отнесение тех или иных правовых средств в разряд мер текущего правового воздействия, действия методом исключения. 
При этом заранее отметим, что правовые средства, образующие гражданско-правовой режим цифровой валюты, могут находится лишь данной группе поскольку основанием для классификации нами изначально было выбрано соотношение с гражданским оборотом во времени. Однако также заметим, что не все нижеперечисленные меры текущего контроля являются правовыми средствами, формирующими гражданско-правовой режим цифровой валюты.

3.1. Признание цифровой валюты имуществом для целей законодательства о противодействии легализации (отмыванию) доходов, полученных преступным путём, и финансированию терроризма. После установления данного правового средства на законодательном уровне Росфинмониторинг, по существу, получает полномочия по оперативному вмешательству в гражданский оборот цифровой валюты уже даже на стадии его осуществления.

Данное правовое средство хоть и может оказывать воздействие на гражданский оборот цифровой валюты, но всё же является внешним по отношению к гражданскому обороту: не формулирует правила его осуществления.

3.2. Лишение права на судебную защиту лиц, требования которых основаны на незадекларированной цифровой валюте. Применение данного правового средства имеет схожий результат с отказом в судебной защите в случае злоупотребления правом, который установлен Гражданским кодексом. Однако среди общего у этих двух правовых средств с юридической точки зрения только правовые последствия, а также возможность применения уже на стадии гражданского оборота цифровой валюты.

С практической точки зрения представляется недостаточно обоснованным отнесение данного правового средства к разряду правовых средств, формирующих гражданско-правовой режим цифровой валюты, поскольку отсутствует зримое воздействие на гражданский оборот: не устанавливаются правила его осуществления. Лишение права на судебную защиту, как и нормы об исковой давности, правильнее было бы отнести в разряд процессуальных норм, как это сделано в некоторых других юрисдикциях.

Но, с другой стороны, если по правовым последствиям применение такого правового средства аналогично отказу в судебной защите при злоупотреблении правом, то и отраслевая принадлежность лишения права на судебную защиту также должна быть аналогичной - гражданско-правовой. Этот вопрос остаётся дискуссионным.
3.3. Закрепление положения цифровой валюты как совокупности электронных данных. В самой дефиниции Закона о ЦФА «цифровая валюта» определяется через родовое понятие «электронные данные», которое нигде в законодательстве в таком виде не используется и, пока отсутствует официальное толкование данной правовой категории, невозможно точно установить правовое содержание этого термина. Таким образом, «цифровая валюта», как новое правовое явление, определяется через родовое понятие «электронные данные», являющееся также новым и нераскрытым термином.

Несмотря на такое неопределённое положение, данное правовое средство всё же имеет весомый потенциал регуляторного воздействия на гражданский оборот, поскольку, по существу, устанавливает ключевой элемент вещно-правового режима цифровой валюты как совокупности электронных данных, но до официального толкования этой правовой категории данное правовое средство остаётся как бы «спящим институтом».

3.4. Дозволение на использование цифровой валюты в качестве средства платежа и (или) инвестиции. Данное правовое средство непосредственно относится к числу средств, формирующих гражданско-правовой режим цифровой валюты, поскольку определяет сферу «разрешённого» использования цифровой валюты и уточняет вещно-правовой режим цифровой валюты, всё более приближая его по функциям к вещно-правовому режиму денег.

3.5. Запрет на приём цифровой валюты в качестве оплаты товаров, работ или услуг. Такое близкое соседство двух вышеперечисленных правовых норм не случайно. На первый взгляд данный запрет полностью нивелирует дозволение на использование цифровой валюты в качестве средства платежа, но строго формально это не совсем так.

Исходя из буквального токования соответствующей нормы пункта 5 статьи 14 Закона о ЦФА следует, что подпадают под действие данного запрета далеко не все сделки и операции. Так, например, А.А. Ситниковым был предложен следующий перечень сделок по обращению цифровой валюты [12]:

- купля-продажа цифровой валюты (если не предполагать расширительное толкование, при котором цифровая валюта также будет отнесена в категорию товар);

- майнинг (как особый вид первоначального основания приобретения права собственности на цифровую валюту);

- сделки в отношении информации или результатов интеллектуальной деятельности (если опять же не применять расширительное толкование, при 
котором и эти правовые объекты будут названы товаром);

- дарение, наследование и иные безвозмездные сделки (поскольку законодатель запрещает лишь совершать сделки, в которых в качестве встречного предоставления за товары, работы или услуги будет предоставлена цифровая валюта, а если встречное предоставление отсутствует, как например, в случае с безвозмездными сделками, то такие сделки строго формально не запрещены);

- внесение в уставный капитал, складочный капитал, фонд (обычно это происходит в форме договора об учреждении или решения единственного учредителя, которые формально не являются возмездными, но, по существу, встречным предоставлением со стороны образуемой организации будет предоставление учредителю доли или акций);

- перевод цифровой валюты самому себе на другой «кошелёк» (такую операцию нельзя признать сделкой, но можно представить, что в последующем этот «кошелёк» будет передан другому лицу вместе со всей находящейся там цифровой валютой, тем более что на настоящий момент техническая возможность такой передачи присутствует).

Комитет Совета Федерации по бюджету и финансовым рынкам в своём Заключении [13] на проект Закона о ЦФА в этот перечень включал куплю-продажу цифровой валюты, мену одной цифровой валюты на другую, а также залог цифровой валюты.

Другими словами, данным правовым средством гражданский оборот цифровой валюты полностью не запрещён, но сфера его легального применения значительно сокращена, что будет чинить существенные препятствия для законопослушных участников гражданского оборота, но будет оставлять значительные правовые пробелы для недобросовестных субъектов.

Такая дихотомия двух вышеперечисленных правовых средств является образцово-показательным примером того, насколько сильно нормы обязательственного права (а данный запрет относится именно к сфере обязательственного права) могут в корне изменить вещно-правовой режим того или иного объекта, в данном случае фактически сведя его на нет.

Таким образом, можно подвести следующие итоги:

1. Элементы гражданско-правового режима цифровой валюты установлены действующим и проектируемым законодательством, но целостной системы гражданско-правовых средств на настоящий момент нет и нет уверенности в скором их принятии.

2. С точки зрения отраслевой принадлежности установленный сейчас и проектируемый в будущем правовой режим можно классифицировать как налогово-правовой, финансово-правовой или даже предпринимательско-правовой, но никак не гражданско-правовой.

3. Закон о ЦФА в части установленных в нём норм, регулирующих отношения в сфере обращения цифровой валюты, нельзя назвать источником гражданско-правового регулирования, поскольку большинство правовых средств данного закона классификационно не могут быть отнесены к разряду гражданско-правовых средств, между нормами Закона о ЦФА и Гражданским кодексом не установлены какие-либо коллизионные или же бланкетные нормы, а также поскольку Законом о ЦФА практически не используется терминология гражданского законодательства.

\section{ЛИТЕРАТУРА}

1. Михайлов А.В. Проблемы становления цифровой экономики и вопросы развития предпринимательского права. М.: Актуальные проблемы российского права, 2018. № 11 (96). С. 69.

2. Федеральный закон от 31 июля 2020 года № 259-Ф3 «0 цифровых финансовых активах, цифровой валюте и о внесении изменений в отдельные законодательные акты Российской Федерации» // Собрание законодательства РФ. — 2020. — № 31. Ч. 1.— - ст. 5018.

3. Проект Федерального закона «0 внесении изменений в части первую и вторую Налогового кодекса Российской Федерации» (в части налогообложения цифровой валюты).— URL: https://sozd.duma.gov.ru/bill/1065710-7 (дата обращения 28.03.2021).

4. Проект Федерального закона «0 внесении изменений в Уголовный кодекс Российской Федерации и Уголовно-процессуальный кодекс Российской Федерации».—URL: https://regulation.gov.ru/p/46853 (дата обращения 28.03.2021).

5. Проекта Федерального закона «0 внесении изменений в Кодекс Российской Федерации об административных правонарушениях».— URL: https:// regulation.gov.ru/p/108949 (дата обращения 28.03.2021).

6. Беляева Г.С. Правовой режим: общетеоретическое исследование: автореферат.— Курск.— 2013.— С. 13.

7. Федеральный закон от 7 мая 2013 года № 79-Ф3 «0 запрете отдельным категориям лиц открывать и иметь счета (вклады), хранить наличные денежные средства и ценности в иностранных банках, расположенных за пределами территории Российской Федерации, владеть и (или) пользоваться иностранными финансовыми инструментами» // Собрание законодательства РФ.— 2013.— № 19.— ст. 2306. 
8. Заключение Комитета Государственной Думы по государственному строительству и законодательству на Проект федерального закона № 1065710-7 «0 внесении изменений в части первую и вторую Налогового кодекса Российской Федерации» (в части налогообложения цифровой валюты).- URL: https://sozd.duma.gov.ru/bill/1065710-7 (дата обращения 28.03.2021).

9. Заключение Комитета Государственной Думы по бюджету и налогам на Проект федерального закона № 1065710-7 «0 внесении изменений в части первую и вторую Налогового кодекса Российской Федерации» (в части налогообложения цифровой валюты).— URL: https://sozd.duma.gov.ru/bill/1065710-7 (дата обращения 28.03.2021).

10. Заключение Правового управления Аппарата Государственной Думы на Проект федерального закона № 1065710-7 «0 внесении изменений в части первую и вторую Налогового кодекса Российской Федерации» (в части налогообложения цифровой валюты).— URL: https://sozd.duma.gov.ru/bill/1065710-7 (дата обращения 28.03.2021).

11. Case C-264/14 Skatteverket v David Hedqvist Judgment of the Court (Fifth Chamber) of 22 October 2015. [ECLI: EU: C:2015:718] // URL: https://eur-lex.europa.eu/ legal-content/EN/TXT/?uri=CELEX\%3A62014CJ0264 (дата обращения: 28.03.2021).

12. Ситник А.А. Цифровые валюты: проблемы правового регулирования. М.: Актуальные проблемы российского права, 2020. № 11. С. 45.

13. Заключение Комитета Совета Федерации по бюджету и финансовым рынкам №3.5-03/1230 от 23 июля 2020 года на проект федерального закона № 419059-7 // Система обеспечения законодательной деятельности.—URL: https://sozd.duma.gov.ru/bill/419059-7 (дата 0бращения: 28.03.2021).

с Никитин Дмитрий Владимирович ( nikitin_d.v@list.ru ).
Журнал «Современная наука: актуальные проблемы теории и практики»

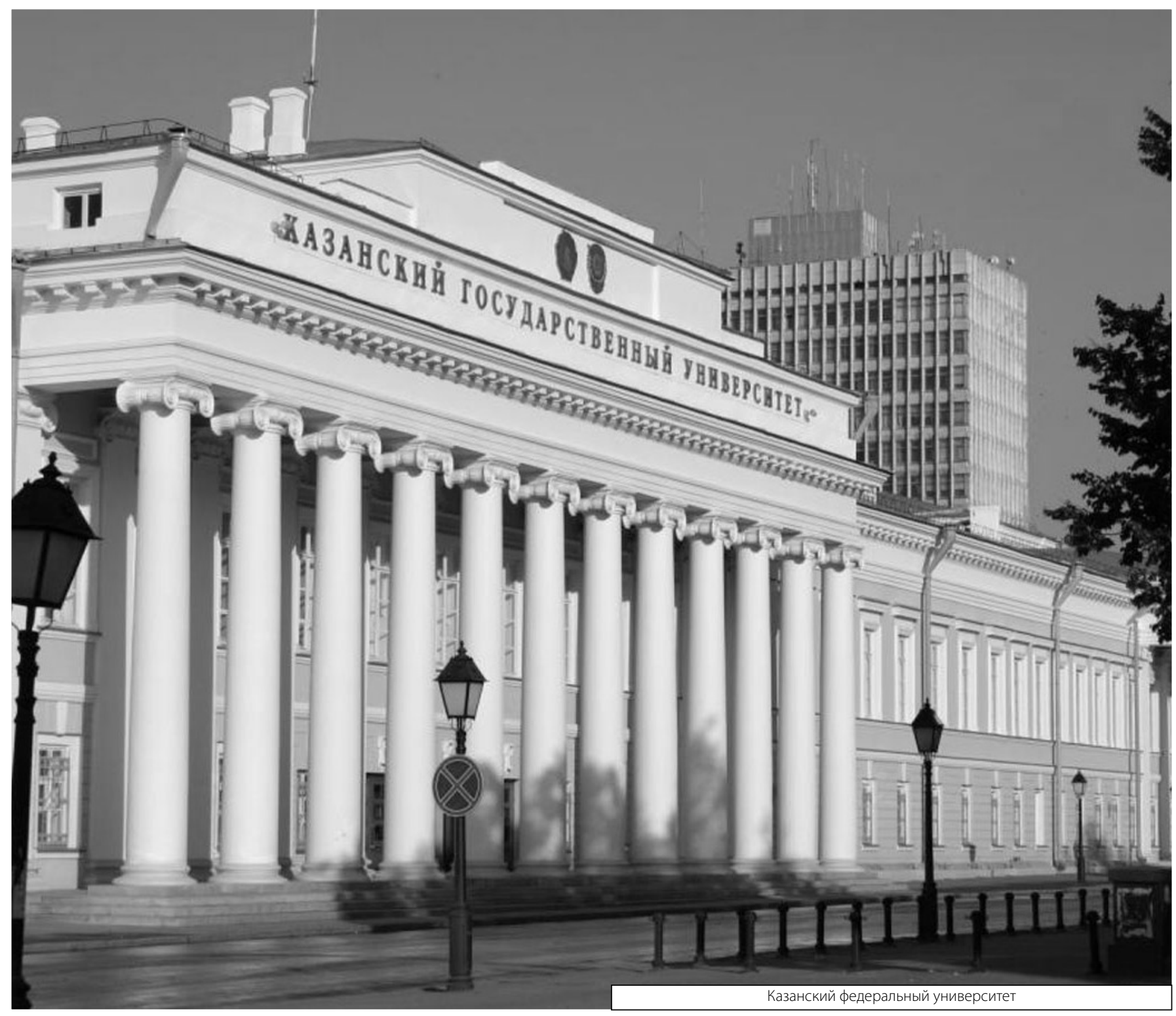

